\title{
Hepatite C
}

\author{
Hepatitis C
}

\author{
Edna Strauss
}

Resumo Estima-se que cerca de 3\% da população mundial esteja infectada pelo vírus da hepatite C. Todos os que receberam transfusão de sangue ou seus componentes e os usuários de drogas podem estar infectados. Procedimentos odontológicos, médicos, tatuagem ou acupuntura também constituem fatores de risco. $A$ infecção se cronifica em até $85 \%$ dos indivíduos, com evolução assintomática durante anos ou décadas e apresentação clínica variada. Para o diagnóstico, a determinação do anti-VHC revela-se muito sensível e a confirmação se faz pela determinação do RNA-VHC no sangue; o estadiamento da doença e a avaliação da atividade inflamatória pela biópsia hepática. O tratamento objetiva deter a progressão da doença hepática através da inibição da replicação viral. Devido à baixa eficácia terapêutica aliada a importantes efeitos colaterais do interferon e da ribavirina, esses medicamentos encontram indicações e contra-indicações específicas. Vários fatores preditivos de resposta ao tratamento, principalmente a carga viral e o genótipo do VHC, mostramse úteis na avaliação dos pacientes.

Palavras-chaves: Hepatite C. RNA-VHC. Interferon. Ribavirina.

\begin{abstract}
It has been estimated that 3\% of the world population is infected with the hepatitis $C$ virus. Those who are blood product recipients or have been illicit drug users are at risk. Dental and medical procedures as well as tattooing and acupuncture are also risk factors. Chronic infection occurs in up to $85 \%$ of infected cases but they may remain without symptoms during years or even decades, and clinical presentation varies. Determination of anti-HCV in sera is a fairly sensitive tool for the diagnosis, and confirmation requires the identification of HCV-RNA. Staging of the liver disease as well as definition of its present activity can be graded by liver biopsy. The aim of treatment is to stop the progression of the hepatic disease by inhibiting viral replication. Due to the low therapeutic efficacy combined with important side-effects, the administration of interferon and ribavirin have specific indications and contraindications. Predictive factors of therapeutic response, particularly viral load and genotypes of $\mathrm{HCV}$, are useful in the evaluation of patients.
\end{abstract}

Key-words: Hepatitis C. RNA-HCV. Interferon. Ribavirin

A hepatite $\mathrm{C}$ vem sendo estudada há vários anos, mesmo antes da descoberta do vírus causador da doença - o Vírus da Hepatite C (VHC) - há 10 anos. Nesta última década, entretanto, houve avanços significativos no entendimento de sua epidemiologia, modos de transmissão, patogênese, diagnóstico e terapêutica.

Sabemos hoje que, a hepatite $\mathrm{C}$ compete com a doença hepática alcoólica como a maior causa de doença crônica do fígado, podendo ser a vencedora em várias áreas geográficas. Estima-se que $3 \%$ da população mundial esteja contaminada, sendo relevante o número de pessoas que desconhece o fato de albergar o vírus. Um estudo populacional na cidade de São Paulo mostrou prevalência de 1 a $4 \%$ de anti-VHC, variando com a faixa etária ${ }^{6}$. As altas porcentagens de cronicidade da doença, seu potencial evolutivo para cirrose e hepatocarcinoma, assim como o fato de ser a mais freqüente etiologia diagnosticada em casos de transplante hepático, fazem com que constitua grave problema de saúde pública.

\section{O AGENTE VIRAL E SUA TRANSMISSÃO}

O VHC é um vírus RNA da família flaviviridae, com genoma em fita simples de polaridade positiva medindo 9,7 kilobases de comprimento (Figura 1). Na poliproteína, com uma longa fase de leitura aberta (open reading frame) distinguem-se as proteínas estruturais: core, E1 e E2 e as não estruturais ou NS (1 a 5), essas últimas responsáveis pela replicação viral. A análise filogenética das seqüências genômicas permitiu a caracterização

Hospital de Clínicas da Universidade de São Paulo (USP), São Paulo, SP

Endereço para correspondência: Dra. Edna Strauss. Divisão de Anatomia Patológica. Av. Dr. Enéas de Carvalho Aguiar, 155 - 10ํandar, $05403-000$ São Paulo, SP.

e-mail: edna.strauss@hcnet.usp.br

Recebido para publicação em 16/10/00. 


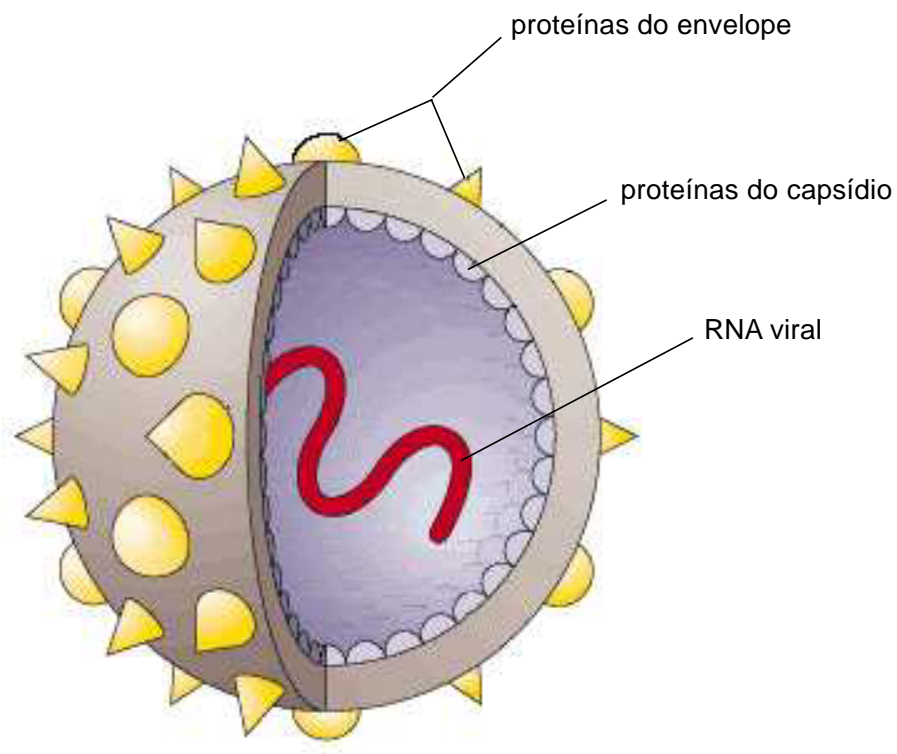

Figura 1 - $O$ vírus da hepatite $C$ é um vírus RNA da família flaviviridae de 50nm de diâmetro.

de 6 genótipos ( 1 a 6 ) que são subdivididos em grupos $a, b, c$, etc. Dentro de um mesmo genótipo e subtipo podemos ainda ter variações do VHC, que são denominadas quasispecies. Isso é possível devido à replicação imperfeita do vírus, com o surgimento de pequenas e constantes mutações. A maior ou menor diversidade das quasispecies parece estar relacionada com a pressão imunológica, já que costuma ser pequena nas fases iniciais da doença, com aminotransferases normais, sendo de alta heterogeneidade nos casos de doença hepática mais avançada e/ou baixa resposta terapêutica ${ }^{29}$.

A grande dificuldade de estudo da hepatite $\mathrm{C}$ reside no fato de ser o VHC um patógeno humano, não havendo animal de experimentação ou meios de cultura que se adaptem à pesquisa, exceto o chimpanzé, de custos proibitivos. Nas poucas investigações experimentais recentes, estudos demonstram que chimpanzés se reinfectam com vírus homólogos e heterólogos, mesmo na presença de anticorpos neutralizantes. Ratos transgênicos que conseguem expressar a proteína do core desenvolveram esteatose hepática no início da infecção pelo VHC, evoluindo posteriormente para carcinoma hepatocelular. Já as proteínas E1/E2, nesse mesmo modelo animal, provocaram o desenvolvimento de manifestações extra-hepáticas, em glândulas salivares e lacrimais, semelhantes à síndrome de Sjögren ${ }^{14}$.

Demonstrou-se que o VHC é o agente causal de mais de $90 \%$ das hepatites pós-transfusionais. Assim, todas as pessoas que receberam transfusão de sangue ou hemocomponentes até o início dos anos 90, com ou sem história de hepatite pós-transfusional, devem ser avaliadas para provável contaminação com o vírus da hepatite C. No Brasil, a partir de 1993, há a obrigatoriedade dos testes sorológicos (anti-VHC) em candidatos a doadores de sangue. Assim, a hepatite pós-transfusional tornou-se rara, mas outros meios, parenterais ou não, continuam a disseminar a doença. Além dos produtos do sangue, agulhas/seringas contaminadas ou mesmo a inalação de drogas - com o uso de espelhos e canudos contaminados - são vias importantes.

Outras formas parenterais de contaminação são os procedimentos médicos, odontológicos, de acupunturista ou de tatuagem. Portanto, qualquer material cortante ou perfurante pode ser veículo transmissor do vírus de uma para outra pessoa, como o alicate da manicura, a lâmina do barbeiro ou mesmo a escova de dentes, compartilhada por cônjuges ou filhos. Em nosso meio ${ }^{39}$, demonstramos que dentre os casos eventualmente rotulados como esporádicos por serem afastados transfusão de sangue ou o uso de drogas ilícitas, houve uma porcentagem significativa de pacientes com cirurgias prévias e/ou atendimentos médicos de urgência em prontos-socorros ou ainda a hipótese já confirmada de contaminação médica durante 0 ato cirúrgico.

Dentre as formas não-parenterais de transmissão da hepatite $C$ torna-se importante de ressaltarmos a possibilidade da transmissão sexual. Embora pouco eficiente, deve-se examinar e alertar o parceiro sexual, particularmente nos indivíduos promíscuos, para os quais é mandatório o uso de preservativos. Aos casais monogâmicos de longa data, sem doenças sexualmente transmissíveis, é facultativo o uso continuado de preservativos, sendo possível a gravidez. Em nossa experiência, como na de vários autores, os índices contaminação do parceiro sexual variam de 6 a $10 \%$. A 
disseminação intrafamiliar também pode existir, possivelmente por compartilharem materiais cortantes ou então pela exposição de ferimentos abertos. A transmissão materno-fetal, tão importante na hepatite $B$, revela-se pouco significativa na hepatite $C$, podendo ocorrer particularmente no momento do parto. Diferentemente da hepatite $B$, não existe profilaxia para o recém-nascido, que terá o anti-VHC da mãe nos primeiros 6 a 12 meses de vida. Nos diferentes estudos, os anticorpos costumam desaparecer nesse período, podendo haver verdadeira contaminação com permanência do RNA-VHC em raros casos, principalmente quando da co-infecção VHC e HIV44.

O tempo de incubação da hepatite $C$ mostra-se bastante variável, de 1 a 13 meses, com média de 8 . Logo após a contaminação, o melhor marcador e único disponível até o presente é a determinação do RNAVHC, já que os anticorpos surgem apenas 4 a 20 semanas após o contágio. Como as formas anictéricas da hepatite
C correspondem a cerca de $70 \%$ dos casos, os indivíduos contaminados evoluem para a cronicidade totalmente assintomáticos, sem terem conhecimento da presença do anti-VHC ou mesmo do aumento de enzimas hepáticas, como a ALT. Nessa fase de janela imunológica ou seja de presença do RNA-VHC ainda com anticorpos negativos pode ocorrer contaminação parenteral, tanto por transfusão sangüínea como pelo uso de drogas ilícitas e outros. Outra situação freqüente é a do acidente com agulha, em pessoal de saúde, ao lidar com enfermos contaminados pelo VHC. Os vários estudos demonstram que as possibilidades de adquirir hepatite $C$ nesses casos mostra-se inferior a 10\%, sendo desejável determinar o RNA-VHC entre 15 e 30 dias após o acidente profissional, pois não há vacina protetora até o momento. A detecção precoce da presença do vírus, sem hepatite aguda clinicamente manifesta, não indica necessariamente o início do tratamento, mas seguimento contínuo, para melhor definição do diagnóstico.

\section{PATOGÊNESE}

Os mecanismos responsáveis pela persistência da infecção pelo VHC não foram ainda elucidados. A existência de quasiespecies e a grande capacidade mutagênica do vírus propiciam o constante escape à intensa resposta imunológica desenvolvida pelo hospedeiro. Assim, cerca de $85 \%$ dos indivíduos infectados evoluem para a cronicidade. A infecção crônica pelo VHC, além de evoluir lentamente, em anos ou décadas, costuma apresentar um amplo espectro clínico, desde formas assintomáticas com enzimas normais até a hepatite crônica intensamente ativa, cirrose e hepatocarcinoma.

A longa evolução da doença, a concomitância de elevada carga viral, a ausência de alterações enzimáticas e alterações histológicas mínimas ou ausentes, constituem dados clínicos contrários ao efeito citopático direto do VHC. Nos últimos anos, diferentes pesquisas têm evidenciado que as lesões hepáticas se relacionam a mecanismos imunomediados. A qualidade da resposta imunológica célula-mediada parece ser crucial para a eliminação ou persistência do VHC, conforme a hipótese mais aceita ultimamente. Os linfócitos TCD4, como se sabe, apresentam respostas distintas Th1 e Th2. Enquanto as células Th1 secretam interleucina 2 e interferon gama estimulando a resposta anti-viral do hospedeiro, as células Th2 produzem interleucinas 4 e 10, que estimulam a formação de anticorpos e inibem a resposta Th1. $O$ desequilíbrio entre as respostas Th1 e Th2 seria responsável tanto pela incapacidade de eliminação do VHC como pela maior ou menor gravidade da lesão hepática. Porém, não se conhecem os elementos que condicionam o desenvolvimento de um ou outro tipo de resposta imunológica ${ }^{24}$.

Outra importante linha de pesquisa na busca de elucidação patogênica da hepatite $C$ é o estudo das interações entre proteínas virais e do hospedeiro. Algumas proteínas do VHC teriam capacidade de disparar um sinal iniciador de processos celulares como proliferação, diferenciação ou apoptose. Recente investigação, confirmando a importância da proteína $X$ do VHB nesse processo, demonstrou ainda que a proteína do core do VHC teria o sinal mais potente para iniciar as alterações celulares ${ }^{15}$.

Além da presença do VHC em linfócitos e monócitos do sangue periférico, foram detectadas faixas negativas de RNA-VHC em células hematopoiéticas, sugeridas como local extra-hepático de replicação do VHC, influindo em sua patogênese ${ }^{19}$. Recentemente descreveu-se uma proteína - CD81 e, que se ligaria à fração E2 (envelope do vírus), funcionando como um receptor ou co-receptor, encontrado tanto em hepatócitos como em linfócitos periféricos ${ }^{27}$. Assim, a neutralização do VHC poderia se fazer por intermédio desse receptor.

A lesão hepatocelular se faz pelo reconhecimento imunológico da célula infectada e sua destruição. A dinâmica desse processo mostra-se extremamente variável, fazendo com que a reação necro-inflamatória do fígado tenha diferentes intensidades. Admite-se que o processo inflamatório contínuo e ineficiente, em termos de eliminação total dos vírus, constitui o principal responsável pela fibrogênese. Entretanto, como não existe uma correlação direta entre processo inflamatório e fibrogênese, outros fatores devem estar envolvidos no desenvolvimento da fibrose hepática, principal fator de progressão da doença.

Argumenta-se que fatores relacionados ao vírus, como carga viral e genótipo, poderiam influenciar a evolução da hepatite crônica pelo VHC. Não existe consenso, entretanto, já que os resultados das pesquisas são divergentes. Enquanto alguns estudos mostram níveis séricos mais elevados em doenças mais avançadas, outros autores demonstraram de forma definitiva que 
podem ocorrer níveis muito altos em pacientes com enzimas normais, sem grandes alterações hepatocelulares ${ }^{20}$. Como os níveis séricos de RNA-VHC não refletem corretamente os níveis de RNA-VHC intra-hepático, tornam-se necessárias investigações sobre essa variável, de mais difícil acesso, assim como estudos sobre a replicação viral. Em relação ao genótipo, o mais freqüente deles - $1 \mathrm{~b}$ é reconhecidamente aquele com pior resposta terapêutica, mas é discutível ser ele causador de lesões hepáticas mais graves. Os estudos iniciais associavam o genótipo $1 \mathrm{~b}$ com evolução mais freqüente para cirrose e hepatocarcinoma, não confirmados quando afastados elementos de confusão como idade, duração da infecção ou forma de aquisição do VHC. Ou seja o genótipo $1 \mathrm{~b}$ associava-se com pacientes mais idosos, com muito tempo de infecção ou nos pacientes com doença adquirida por via transfusional. Estudos mais recentes demonstram que a distribuição dos diferentes genótipos pode ser semelhante em pacientes com enzimas séricas normais comparados àqueles com enzimas aumentadas ${ }^{1}$.

A progressão da lesão hepática, da hepatite crônica para cirrose, pode ainda relacionar-se a fatores do hospedeiro, ou seja, sexo, idade, uso de álcool ou concomitância com outros vírus. O mais importante dos fatores do hospedeiro, entretanto, parece ser o seu estado imunológico. Assim, uma resposta imunológica vigorosa pode eliminar o VHC em 15\% dos indivíduos que entram em contato com ele, enquanto em pacientes crônicos, ou imunossuprimidos a doença evolui mais rapidamente para cirrose e hepatocarcinoma quando comparada aos imunocompetentes. Portanto, após transplantes hepáticos por cirrose com VHC, recomenda-se que a terapia imunossupressiva seja a menor possível ${ }^{5}$. Na co-infecção VHC-HIV, a progressão da doença revela-se mais rápida, se comparada aos pacientes HIV negativos ${ }^{38}$, de forma semelhante ao que ocorre na co-infecção com o vírus da hepatite $B$.

Fatores hormonais e genéticos devem estar implicados na patogênese da hepatite pelo $\mathrm{VHC}$, sendo aceito que a doença costuma progredir mais rapidamente no sexo masculino. A idade do paciente ao adquirir a infecção também mostra-se relevante, havendo pior prognóstico naqueles com idade superior a 40 anos. Outro importante fator, variável independente no prognóstico evolutivo da fibrose hepática, é o consumo alcoólico. Os mecanismos, não bem elucidados, envolvem aumento de carga viral induzida pelo álcool, assim como lesões imunomediadas e hepatotóxicas ${ }^{26}$

\section{DIAGNÓSTICO}

O teste sorológico para diagnóstico de hepatite $\mathrm{C}$, rotineiramente utilizado desde o início dos anos 90, é um teste imunoenzimático (ELISA) para detecção de anticorpos contra o vírus da hepatite $\mathrm{C}$ (anti-VHC), que adquiriu maior sensibilidade e especificidade ao passar de testes de primeira para segunda e terceira gerações (ELISA II ou III). Embora extremamente útil para o diagnóstico das hepatites crônicas, especialmente nos pacientes com alterações de transaminases e epidemiologia sugestiva de VHC, o ELISA costuma apresentar resultado negativo nos primeiros meses após a contaminação, dificultando o diagnóstico etiológico nas fases iniciais da hepatite aguda pelo VHC ou mesmo falseando um resultado negativo em doadores de sangue contaminados. Por outro lado, persiste a possibilidade de resultado falsamente positivo em doadores de sangue ou qualquer grupo de indivíduos com baixo valor preditivo de contaminação pelo VHC.

Assim sendo, nos casos ou grupos com valor preditivo alto para a infecção pelo $\mathrm{VHC}$, a reatividade do teste pelo ELISA possui valor diagnóstico definitivo. Na dúvida, porém, é possível requisitar testes confirmatórios do ELISA, como o Imunoblot (RIBA e INNOLIA). A realização desses testes revela-se particularmente útil no descarte de falsos-positivos em populações de baixo risco ${ }^{9}$. A Figura 2 apresenta um algoritmo com os exames a serem solicitados em cada etapa, de acordo com a análise conjunta dos dados clínicos e laboratoriais ${ }^{30}$ (Figura 2).

As técnicas de biologia molecular, para detecção direta do RNA do VHC, embora menos acessíveis, mais complexas e onerosas, ganharam espaço e se firmaram como necessárias para confirmação diagnóstica. Elas são particularmente úteis para comprovar a presença de viremia nas exposições recentes, fases iniciais da hepatite aguda, nos imunossuprimidos assim como em pacientes de risco com reatividade para o anti-VHC e ALT normal.

A reação em cadeia da polimerase (PCR) é uma das técnicas de biologia molecular mais utilizadas, que amplifica parte do genôma do vírus, sendo extremamente sensível. No entanto, devido a problemas de especificidade e precisão, apresentaram porcentagens significativas de erros em estudos duplo-cegos ${ }^{45}$. Outra variante técnica é aquela que, em vez de parte do genoma viral amplificase o sinal de sua presença, conhecida como branched DNA (bDNA), muito mais reprodutíveis, porém menos sensíveis do que a PCR. Assim, nas cargas virais altas as quantificações pelo bDNA mostram-se mais reprodutíveis do que pela PCR, embora essas últimas sejam mais sensíveis, podendo diagnosticar pequeno número de cópias (acima de 500 ou 2000 cópias), sendo por isso preferidas pela maioria dos investigadores ${ }^{4}$.

Para confirmação diagnóstica de hepatite $\mathrm{C}$ aconselhase a determinação qualitativa do RNA-VHC, de preferência pelo método da PCR. As determinações quantitativas (carga viral), por outro lado, mostram-se muito interessantes antes do início do tratamento, juntamente com a determinação do genótipo, para definir-se a duração do tratamento. Elas também são utilizadas para monitorizar a resposta terapêutica ou para acompanhamento de casos não tratados. 


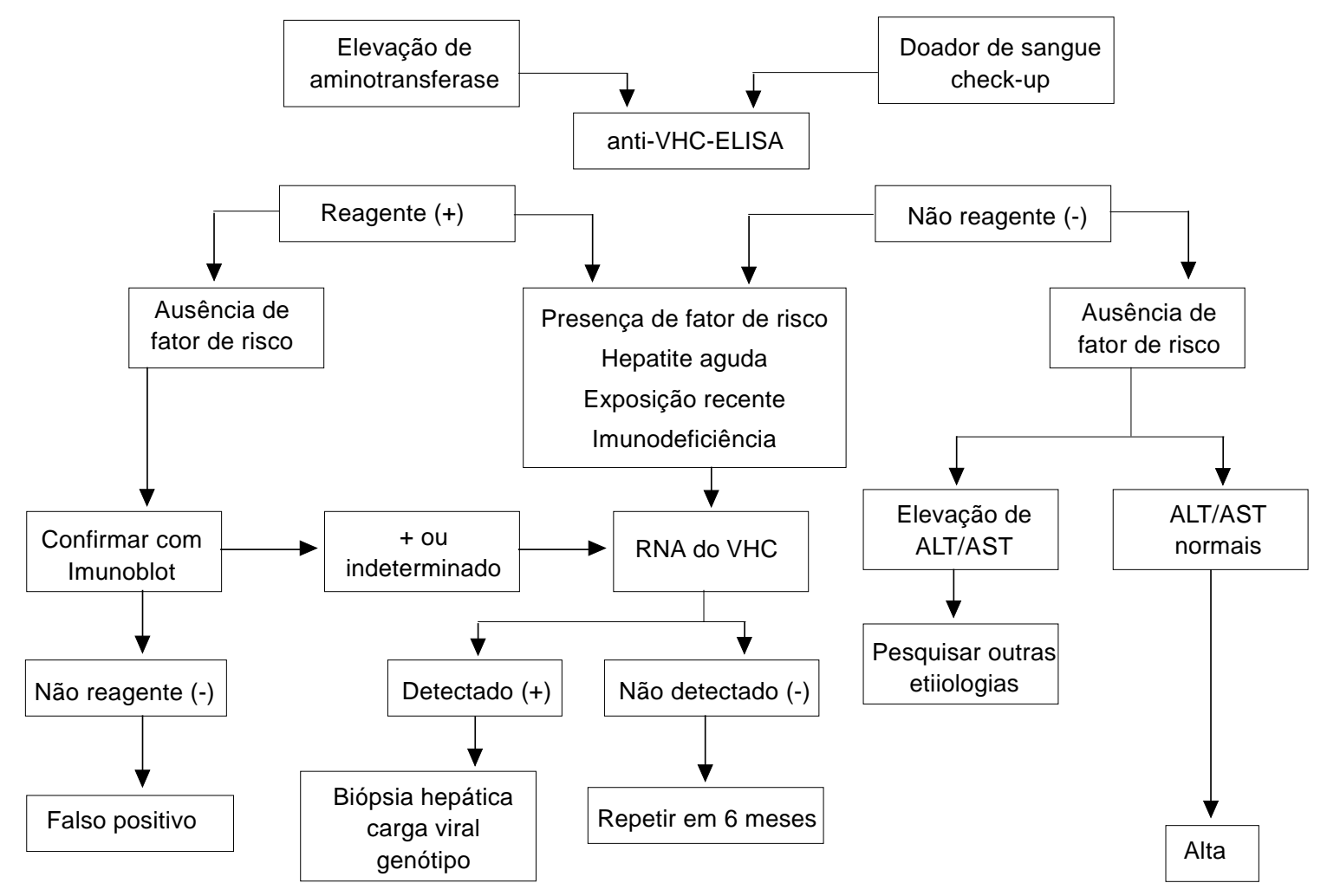

Fígura 2 - Algoritmo para confirmação diagnóstica de Hepatite $C^{30}$.

O desenvolvimento de testes imunoenzimáticos para detecção do antígeno core do VHC apresenta como principal vantagem sua realização em laboratórios nãoespecializados, com diminuição de custos e a possibilidade de substituir a complexa determinação do RNA-VHC. Os testes de primeira geração foram aperfeiçoados, aumentando a sensibilidade e simplificando as etapas de pré-testes da amostra, podendo vir a ser utilizados em breve. Estudos recentes mostram detecção precoce do antígeno core na hepatite $\mathrm{C}$ aguda, correlação significativa entre seus níveis e aqueles do RNA-VHC nas hepatites crônicas e durante o seu tratamento ${ }^{40}$.

O diagnóstico histológico revela-se importante quando da decisão terapêutica e também fornece subsídios quanto à confirmação da etiologia pelo VHC. Assim, a biópsia hepática está sempre indicada nos casos com marcadores virais positivos para o $\mathrm{VHC}$ e aumentos de ALT. Já nos casos de ALT persistentemente normal, mesmo com marcadores sorológicos confirmando a presença do VHC, aconselha-se apenas a monitorização constante com determinações de ALT a cada 3 meses, mudando-se a conduta quando de sua elevação. As enzimas podem manter-se em níveis normais durante vários anos, havendo ainda a rara hipótese de soroconversão espontânea, ou seja negativação do RNA-VHC ao longo do tempo ${ }^{10}$.

No consenso da Sociedade Brasileira de Hepatologia, os patologistas brasileiros utilizam uma mesma classificação para estadiamento e graduação das hepatites crônicas (Tabela 1) ${ }^{7}$. A partir da biópsia hepática, requerida por várias Secretarias de Saúde no Brasil, indica-se o uso dos antivirais nos casos com estadiamento mostrando fibrose em evolução e atividade inflamatória moderada ou intensa. Oficialmente, não há indicação de tratamento antiviral para os indivíduos com estrutura hepática normal, fibrose mínima ou ausente e atividade inflamatória leve. Logicamente, esses consensos são dinâmicos e poderão vir a ser modificados, assim que surjam medicamentos mais eficazes e com efeitos colaterais menos intensos.

\section{HISTÓRIA NATURAL}

A determinação da história natural da hepatite $C$ é de difícil avaliação devido a vários fatores: escassez de estudos prospectivos, freqüente imprecisão dos dados sobre a época da contaminação, curso longo e assintomático da doença. Além desses, existem os fatores de confusão, tanto ambientais como etilismo crônico e co-infecções, como virais (diferentes genótipos e cargas virais), ou fatores do hospedeiro, entre eles os fatores imunológicos.

Trabalhos retrospectivos ${ }^{17}{ }^{41}$, utilizando grandes casuísticas de hepatites pós-transfusionais, estipularam 
Tabela 1 - Critérios para a semiquantificação de alterações histológicas nas hepatites crônicas

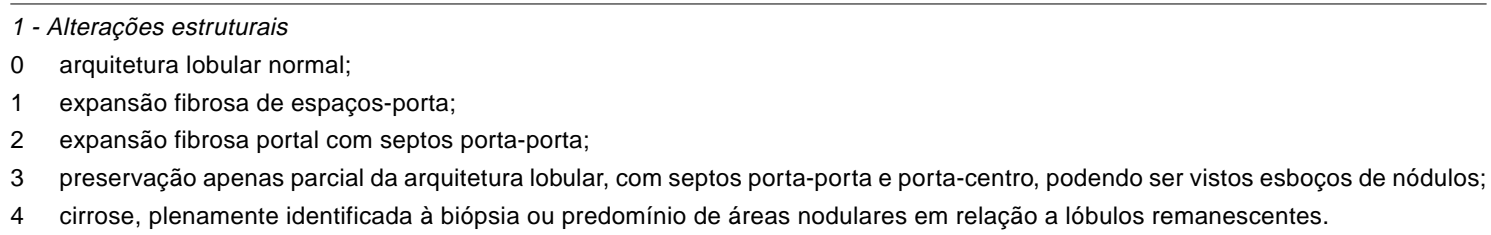

\section{2 - Infiltrado Inflamatório Portal/Septal}

Semiquantificação de 0 a 4, independentemente da formação de folículos linfóides.

0 . raros linfócitos portais;

1. aumento discreto do número de linfócitos portais;

2. aumento moderado do número de linfócitos portais

3. aumento acentuado do número de linfócitos portais;

4. aumento muito acentuado do número de linfócitos portais.

3 - Atividade Peri-Portal/Peri-Septal

0. ausência de lesões da interface espaço-porta/parênquima;

1. extravasamento de linfócitos para a interface (spill-over), não caracterizando a presença de necrose em saca-bocados;

2. necrose em saca-bocados discreta (pequenas áreas em poucos espaços-porta);

3. necrose em saca-bocados moderada (extensas áreas em poucos espaços-porta ou pequenos focos em muitos espaços-porta);

4. necrose em saca-bocados em extensas áreas de muitos espaços-porta

4 - Atividade Parenquimatosa

0 . hepatócitos normais, isomorfos:

1. alterações discretas de hepatócitos, incluindo tumefação ou retração acidofílica, eventualmente acompanhada de infiltrado linfohistiocitário, e raros focos de necrose;

2. necrose focal de hepatócitos circundados por agregados linfo-histiocitários em numerosos sítios

3. necrose focal de hepatócitos circundados por agregados linfo-histiocitários em muitos sítios, associada a áreas limitadas de necrose confluente

4. necrose focal de hepatócitos circundados por agregados linfo-histiocitários em numerosos sítios, associada a necrose confluente extensa/múltipla.

que o tempo médio para desenvolvimento de hepatite crônica variou de 10 a 13 anos, de cirrose 21 anos e de carcinoma hepatocelular de 29 anos (Figura 3). Nos poucos estudos prospectivos, com baixos percentuais de cronicidade, o tempo de seguimento é pequeno. Um importante estudo comparou índices de mortalidade em pacientes com hepatite pós-transfusional e seus controles não encontrando diferenças estatisticamente significantes, embora os percentuais de doença hepática $(3,3 \%)$ fossem maiores que os respectivos controles $(1,1 \%)^{32}$. Em outro estudo, um grupo homogêneo de mulheres jovens, infectadas pelo VHC ao receberem imunoglobulina anti- $D$, foram estudadas 17 anos após a infecção, sendo demonstradas alterações hepáticas muito discretas e em apenas $2 \%$ delas havia cirrose ${ }^{16}$. Todos esses trabalhos apontam para uma evolução lenta da infecção pelo VHC, embora haja relatos de casos com progressão mais acelerada, usualmente relacionados aos fatores de pior prognóstico já mencionados.

\section{TRATAMENTO}

O tratamento da hepatite $C$ objetiva deter a progressão da doença hepática pela inibição da replicação viral. A redução da atividade inflamatória costuma impedir a evolução para cirrose e carcinoma hepatocelular, havendo também melhora na qualidade de vida dos pacientes. Os medicamentos disponíveis até o momento, entretanto, nos mais diversos esquemas em termos de doses, duração ou associações conseguem atingir os objetivos propostos em menos da metade dos pacientes tratados. Embora ainda desanimadora, a situação atual representa a melhor possível, se comparada à atitude expectante de apenas 10 ou 15 anos atrás. A precocidade do diagnóstico nos leva a tratar pacientes freqüentemente assintomáticos, impedindo que quase a metade deles evoluam para fases sintomáticas da doença hepática, de mais difícil controle.

Além da baixa eficácia terapêutica, os medicamentos disponíveis a saber, Interferon e Ribavirina, provocam efeitos colaterais importantes e devem ser administrados por período de tempo prolongado, exigindo monitorização médica especializada constante. Considerando que a 


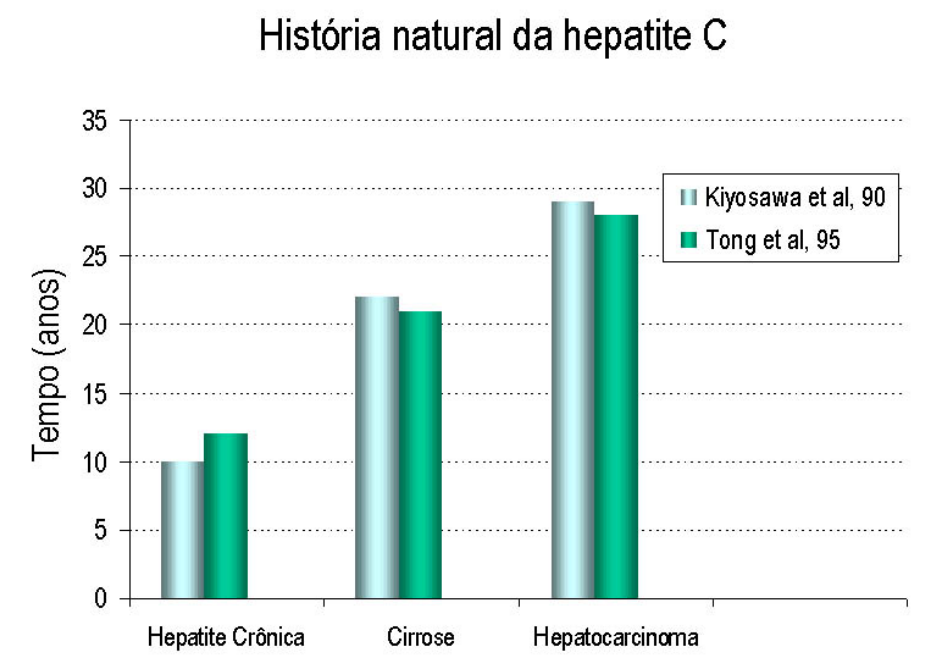

Figura 3 - Tempo de evolução em anos, após hepatite pós-transfusional1741.

história natural da doença não é bem conhecida, havendo a possibilidade concreta de indivíduos infectados evoluirem com lesões hepáticas mínimas por várias décadas e apenas $20 \%$ chegarem à fase cirrótica, o tratamento deve ter indicações específicas. Outro aspecto a ser considerado é o alto custo do processo terapêutico, onerando não apenas os indivíduos acometidos mas toda a sociedade, já que em nosso país existe a distribuição dos medicamentos pelo Sistema Único de Saúde.

\section{INDICAÇÕES TERAPÊUTICAS}

A hepatite $C$ aguda, particularmente aquela com síntomas e icterícia, apresenta grande probabilidade de evoluir para as formas crônicas, e merece tratamento. Alguns estudos demonstraram, com o uso isolado do Interferon, eficácia em cerca de $50 \%$ dos casos, percentuais esses que devem aumentar com a combinação de interferon e ribavirina. Embora não exista consenso quanto ao melhor esquema terapêutico, em termos de doses ou duração, aceita-se postergar o tratamento até três ou seis meses após o início dos sintomas.

A presença de marcadores do $\mathrm{VHC}$, tanto o anti-VHC como o RNA-VHC, mesmo que por tempo superior a seis meses, porém, sem concomitante aumento de transaminases ou história sugestiva de hepatite aguda, não caracteriza hepatite crônica. Não se indica biópsia ou tratamento aos pacientes com níveis persistentemente normais de ALT. Os poucos estudos terapêuticos realizados nesses casos não foram convincentes, mostrando pouca eficácia ou mesmo exacerbação do processo com o uso do Interferon ${ }^{21}$. Faz-se necessário, entretanto, o seguimento cuidadoso desses pacientes, que podem vir a apresentar alterações enzimáticas que justifiquem a biópsia hepática e posterior início do tratamento. Por outro lado, alguns estudos demonstraram a possibilidade de haver lesão hepática (atividade inflamatória e fibrose), mesmo na presença de ALT persistentemente normal.

Como relatado anteriormente, a biópsia hepática constitui importante parâmetro para a definição terapêutica.
Níveis pouco aumentados de ALT, entre 2 a 3 vezes o valor máximo normal, podem corresponder a alterações leves, moderadas ou intensas em termos de atividade inflamatória, com graus igualmente variáveis de fibrose hepática. As decisões do consenso americano de $1997^{25}$, ratificados no europeu em $1999^{4}$, concordam em indicar tratamento apenas nos casos com atividade inflamatória moderada ou intensa, associada a presença de septos de fibrose. Assim, aos casos sem fibrose hepática (ou com fibrose restrita aos espaços porta) e com atividade inflamatória leve não se indica tratamento antiviral. A monitorização clínica inclui determinações seriadas - 2 a 4 vezes ao ano - das enzimas hepáticas, determinações de carga viral (1 a 2 vezes ao ano) e novas biópsias a cada 1 a 5 anos $^{25}$.

Os casos clássicos de hepatite crônica, com atividade histológica moderada/intensa, constituem a populaçãoalvo a ser tratada. Embora ainda assintomáticos, esses pacientes iniciaram uma reação imunológica intensa contra o VHC, testemunhada pela lesão histopatológica. Nessa fase, o auxílio externo proporcionado pelos antivirais, com ação também imunomoduladora, têm maiores probabilidades de serem eficazes do que nos indivíduos que aparentemente convivem com os vírus, sem sinais de reação tecidual, ou seja, doença hepática.

Como a evolução da hepatite crônica para cirrose mostra-se insidiosa, o resultado da biópsia poderá surpreender tanto o paciente como o próprio médico. 
Durante algum tempo houve certa resistência em indicar tratamento para pacientes com cirrose estabelecida, já que um de seus objetivos seria impedir essa evolução. A inclusão de pacientes cirróticos em diversos estudos randomizados demonstrou ainda que a eficácia terapêutica, nesses casos, era extremamente baixa, cerca de $5 \%{ }^{42}$. Por outro lado, o paciente com cirrose compensada pode estar totalmente assintomático e o objetivo do tratamento seria impedir a continuidade da lesão hepática, que leva tanto à descompensação clínica como ao carcinoma hepatocelular. Nesse sentido, enquanto o consenso americano contra-indicava o tratamento em cirróticos o consenso europeu, dois anos depois, aceita que a cirrose compensada seja tratada, com cautela.

\section{CONTRA-INDICAÇÕES E EFEITOS COLATERAIS DO INTERFERON (IFN) E DA RIBAVIRINA}

O grupo de pacientes com indicação de tratamento para a hepatite $C$ deve ser avaliado quanto a eventuais contra-indicações específicas ao uso tanto do IFN quanto da ribavirina.

As contra-indicações ao uso do IFN podem ser absolutas ou relativas, não havendo consenso entre os autores. Estados depressivos, por exemplo, são considerados por muitos como contra-indicação absoluta, pela tendência suicida embutida nesses quadros. Para outros, ela seria uma contra-indicação relativa, desde que monitorizada adequadamente por psicoterapêutas. Já as psicoses graves ou convulsões incontroláveis constituem contra-indicações absolutas. Neutropenia e/ou plaquetopenia também representam contra-indicações, já que a medicação irá acentuar essas alterações. Nos casos leves, entretanto, é possível iniciar o IFN com avaliações seriadas e redução de doses, sempre que necessário. Durante o tratamento, deve-se procurar manter a contagem de neutrófilos acima de $1000 / \mathrm{mm}^{3}$ e de plaquetas acima de $40.000 / \mathrm{mm}^{3}$. A cirrose descompensada também constitui contra-indicação ao uso de IFN, assim como o transplante de orgãos, particularmente de rins. Mesmo no transplante hepático, quando há recidiva da hepatite $\mathrm{C}$, o uso de IFN tem sido questionado, pelas possibilidades relatadas de rejeição.

Outras contra-indicações revelam-se relativas como etilismo atual ou continuidade do uso de drogas ilícitas. Quando da concomitância de doenças auto-imunes o uso de IFN costuma ser deletério, devendo portanto ser indicado com muito critério. O diabetes mellitus, doença freqüente e muitas vezes associada à hepatite $C$, pode piorar durante o uso de IFN ou ser desencadeado pelo mesmo. Adotamos a conduta de não iniciar IFN antes de conseguir um bom controle clínico do diabetes, que deve ser monitorado durante todo o tempo de tratamento da hepatite $\mathrm{C}$.

A idade do paciente, ou seja acima de 65-70 anos pode ser um fator de dúvida e a conduta deve ser tomada caso a caso. Para a população infantil, abaixo de 15 anos, também não existe consenso. Diferentes estudos controlados mostram eficácia do IFN semelhante àquela dos adultos, porém com efeitos colaterais peculiares à faixa etária, não sendo conhecidos seus efeitos sobre o crescimento. Pelo curso benigno e prolongado da doença, o acompanhamento clínico constitui a conduta mais aceita. Nos casos mais avançados o tratamento deve ser realizado em centros especializados, de preferência como parte de ensaios clínicos controlados ${ }^{30}$.
Além dessas contra-indicações cumpre reafirmar que o IFN produz efeitos colaterais importantes, cujo conhecimento deve ser compartilhado por médicos e pacientes. Na Tabela 2 encontram-se os principais efeitos colaterais de IFN e Ribavirina. Nas primeiras doses pode ocorrer hipertermia, dores musculares e articulares, astenia intensa, cefaléia e distúrbios digestivos como náuseas ou vômitos. Esses sintomas, mais intensos na primeira dose, vão amenizando após a primeira semana, mas só desaparecem totalmente com a suspensão da medicação. Nas primeiras semanas já é possível controlar os efeitos sobre o hemograma, verificando eventuais quedas de leucócitos e/ou plaquetas; a seguir, esse controle deve ser mensal, durante todo o tratamento (Tabela 2).

Com o uso da medicação os sintomas neuropsicológicos podem se acentuar: irritabilidade, desânimo, instabilidade emocional, depressão, etc. Deve-se ainda cuidar de eventuais alterações auto-imunes, tanto para o lado do diabetes, como da função tireoidiana, podendo ocorrer tanto hipo como hipertireoidismo. A queda de cabelos é dose dependente, não sendo muito intensa nas doses habituais de 3 milhões de unidades, 3 vezes por semana.

Outros sistemas orgânicos podem ser alterados com o uso contínuo de IFN produzindo, mais raramente, alterações dermatológicas, cardio-vasculares, pulmonares, renais, auditivas ou oftálmicas ${ }^{2}$.

A ribavirina, atualmente usada em concomitância com o IFN para maior eficácia terapêutica, também apresenta contra-indicações específicas. Quando administrada por via oral, os estudos farmacocinéticos recentes demonstram que ela é transportada para o interior de todos os tipos de células do corpo, inclusive óvulos e espermatozóides. Seu metabolismo intracelular inclui etapas de fosforilação para posterior eliminação, com meia-vida aproximada de 300 horas, após múltiplas doses. Dessa forma, os conhecidos efeitos teratogênicos da droga só cessam 6 meses após sua descontinuidade. As pessoas em idade fértil devem usar métodos anticoncepcionais seguros, tanto no sexo masculino como feminino durante todo o tratamento e 6 meses após o mesmo ${ }^{8}$. É de responsabilidade do médico averiguar se o paciente tem condições de seguir essa importante orientação.

O uso de ribavirina leva, freqüentemente, à anemia de padrão hemolítico. Sabemos hoje que isto deve-se à maior permanência da droga nos eritrócitos que por serem desprovidos de núcleo tornam-se muito lentos 
Tabela 2 - Efeitos colaterais do interferon e ribavirina².

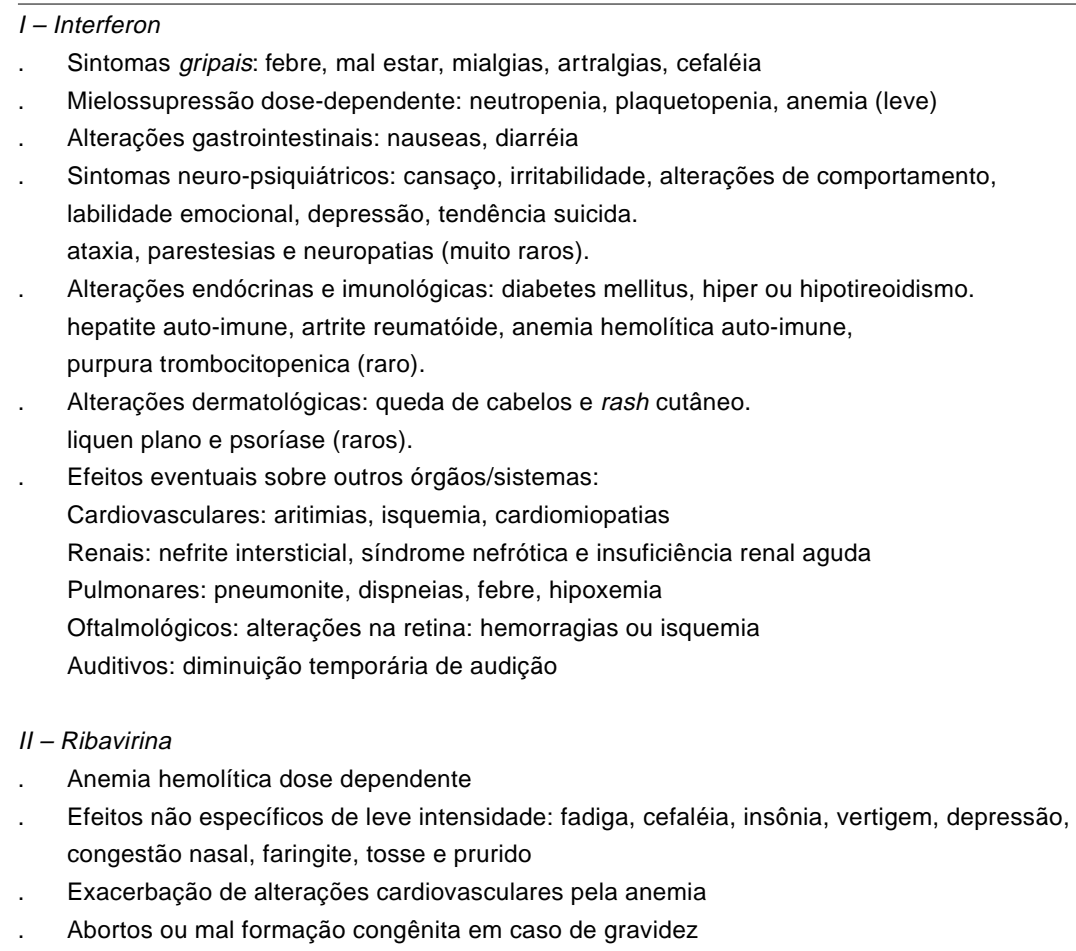

em realizar o processo de fosforilação necessário para sua eliminação, provocando assim hemólise extravascular ${ }^{13}$. Desta forma, casos com anemia de base ou com hemoglobinopatias constituem contra-indicação ao uso de Ribavirina. Também as doenças cardíacas impedem o uso da droga, assim como a hipertensão arterial grave. Como a eliminação da ribarivina se faz por via renal os casos de insuficiência renal ou rebaixamento do clearance de creatinina $<50 \mathrm{ml} /$ minuto sofrem sérias restrições. O medicamento pode ser ingerido com alimentos, inclusive ricos em lipídios, mas ocorre redução de sua biodisponibilidade em casos de uso associado a antiácidos ${ }^{8}$.

O principal efeito colateral da ribivirina é a anemia de padrão hemolítico, que se desenvolve nas primeiras 4 semanas de sua administração, sendo dose-dependente. Sempre que os níveis de hemoglobina caírem abaixo de $10 \mathrm{~g} \%$ faz-se necessária a diminuição de doses ou sua suspensão, conforme o caso clínico. Outros efeitos colaterais, pouco específicos, costumam ser leves e raros: cansaço, cefaléia, insônia, náuseas, congestão nasal, faringite, tosse e prurido.

\section{ESQUEMAS TERAPÊUTICOS}

Os primeiros estudos terapêuticos com Interferon datam de $1986^{12}$, antes da descoberta do VHC, na época da hepatite não-A, não-B. Inicialmente, diferentes doses chegaram a ser utilizadas, porém a conduta mais freqüente foi a administração de IFN 3MU três vezes por semana, durante 6 meses. Ficou evidente que doses menores eram ineficazes enquanto doses mais elevadas, com efeitos colaterais mais acentuados, eram menos toleradas pelos pacientes.

O conceito de eficácia terapêutica também evoluiu com o tempo, sendo definidos 3 padrões atualmente aceitos: a) resposta completa é aquela avaliada logo ao final do tratamento, definida como normalização bioquímica e/ou negativação do RNA-VHC; b) não-resposta é a permanência de ALT elevada e/ou a presença do RNAVHC, mesmo que tenha havido queda de seus níveis e, c) resposta sustentada representa a manutenção de resposta completa durante período de tempo maior que 6 meses após a interrupção do tratamento. Como nem sempre existe concordância entre níveis de ALT e os resultados do RNA-VHC, aceita-se que o melhor parâmetro é a negativação do RNA-VHC por método sensível de PCR (qualitativo). Considerados esses tipos de resposta, a falha terapêutica pode ser tanto por não-resposta como por recaída, ou seja, ressurgimento da infecção após uma resposta completa.

Ao revisarmos trabalhos da primeira metade dos anos 90 deparamos com índices de eficácia terapêutica 
em torno de $20 \%$ a $30 \%$, que caíram para $5 \%$ a $10 \%$ nos últimos grandes estudos controlados, em decorrência de mudanças nos critérios de resposta e maior sensibilidade dos métodos de PCR, substituindo a simples normalização da ALT. Face a esses baixos índices de eficácia terapêutica testaram-se, ainda, como monoterapia, doses mais elevadas de IFN. A definição para dose mais elevada de IFN é toda aquela superior a 3MU três vezes/semana ou $9 \mathrm{MU} /$ semana. Assim, doses de 4,5MU, 5MU, 6M e 10MU foram testadas tanto em aplicações 3x/semana como em uso diário de 1993 a 1998 em 19 estudos (apenas casuísticas $>50)^{34}$. A soma dos resultados mostrou que, embora a resposta completa fosse melhor, a resposta sustentada não foi significativamente diferente dos clássicos 3MU. Outro objetivo das investigações tem sido o tempo de uso do IFN, havendo uma sensível diferença na comparação entre 6 e 12 meses, com vantagens para o último, que passou a ser amplamente utilizado.

Dentre os diferentes tipos de interferons, os mais utilizados na hepatite $\mathrm{C}$ são o IFN $\alpha 2 b$ e $\alpha 2 a$, embora o IFN $\beta$, o linfoblastóide e o IFN consensus também possam ser utilizados. Em termos de eficácia terapêutica há equivalência entre os tipos $\alpha 2 b$ e $\alpha 2 a$, nas doses equivalentes de 3 a $10 \mathrm{MU}$, enquanto o IFN consensus nas doses de 9 a $15 \mu \mathrm{g}$ são preferidos no tratamento de recaídas ou em não respondedores ${ }^{11}$.

Devido à limitada eficácia da monoterapia com IFN, várias outras drogas com propriedades anti-virais têm sido testadas no tratamento da hepatite $\mathrm{C}$, quer como monoterapia quer associadas ao IFN. O uso isolado de ribavirina, um nucleosídeo sintético análogo da guanosina, provoca queda de transaminases porém com pouca ou nenhuma alteração dos níveis de RNA-VHC, quando utilizada durante 12 meses. Amantadina, rimantadina, ácido ursodeoxicólico e anti-inflamatórios não hormonais foram testados isoladamente ou associados ao Interferon, com resultados pouco animadores ${ }^{43}$.

Além da ação antiviral, tanto o IFN como a Ribavirina também são imunomoduladores, regulando portando a resposta imunológica no processo de eliminação viral. A timosina alfa 1 é um imunomodulador específico, estimulando células NK, produção de linfócitos CD8 assim como aumento de resposta Th1 das células CD 4. Apesar disso, o uso clínico isolado de timosina tem sido ineficaz contra o VHC, embora sua associação com IFN apresente melhores resultados ${ }^{33}$.

Dentre todas as associações testadas até o presente apenas aquela de IFN e ribavirina produziu resultados consistentes em termos de sensível aumento percentual de resposta sustentada. Nos estudos iniciais, a combinação de IFN 3MU 3 x/semana e ribavirina 1 a $1,2 \mathrm{~g} /$ dia foi utilizada em casos de recaída ou não resposta ao uso isolado de IFN. Os bons resultados obtidos, particularmente nas recaídas, levou a dois grandes estudos multicêntricos, um americano ${ }^{22}$ e outro internacional ${ }^{28}$, comparando IFN isolado e associação como primeira opção de tratamento, durante 6 ou 12 meses. O caráter multicêntrico desses estudos permitiu avaliar essa terapêutica em 1.744 pacientes com hepatite crônica pelo VHC. Os índices de resposta sustentada foram de $13 \%$ e $19 \%$ com o uso isolado de IFN por 12 meses, de $31 \%$ e $35 \%$ com a associação IFN e ribavirina durante 6 meses e de $38 \%$ e $43 \%$ com a combinação de drogas durante 12 meses (Figura 4).

\section{Índices de resposta sustentada na associação terapêutica Interferon (IFN) e Ribavirina (Riba)}

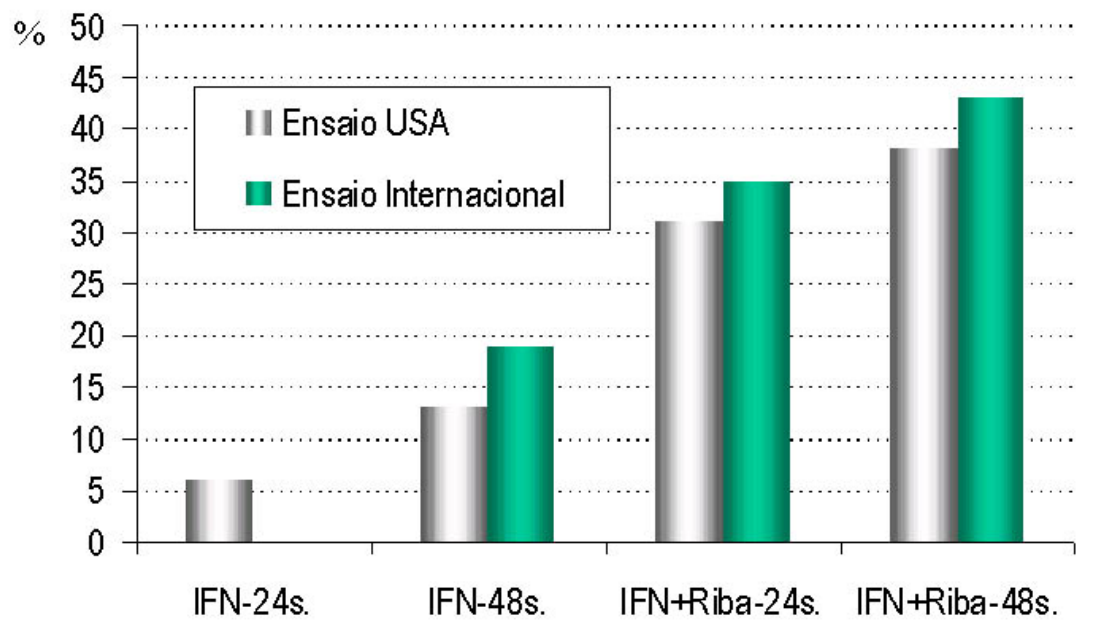

Figura 4 - Resultados dos dois ensaios terapêuticos com total de 1.744 casos de hepatite C crônica estudados ${ }^{22} 28$. 
O grande número de pacientes em cada grupo de tratamento e a similaridade de critérios nos dois estudos permitiu uma avaliação conjunta da influência tanto do genótipo do VHC como de sua carga viral para a obtenção de resposta sustentada. Na Tabela 3 estão listadas as respectivas porcentagens de resposta para genótipos 1 ou não-1 assim como para cargas virais até $2 \times 10^{6}$ ou $>2 \times 10^{6}$. Essa análise evidencia que nos genótipos diferentes de 1 os porcentuais de resposta sustentada (60\% a $64 \%$ ) não melhoraram prolongandose o tratamento por 12 meses, independentemente da carga viral. Para os genótipos do tipo 1 (1b e 1a) a carga viral $<2 \times 10^{6}$ também não apresentou sensíveis diferenças quando comparados 6 e 12 meses de tratamento $(32 \%$ e $33 \%$ ), mas os resultados aos 12 meses foram expressivamente melhores para pacientes com genótipo 1 e cargas virais altas, ou seja $27 \%$ contra $10 \%$ no grupo tratado por apenas 6 meses $^{23}$ (Tabela 3).

Tabela 3 - Resposta terapêutica sustentada e sua relação com genótipo e carga viral${ }^{23}$.

\begin{tabular}{lccccc}
\hline Genotipo & HVC-RNA & $\begin{array}{c}\text { IFN+Placebo } \\
\text { (24 semanas) }(\%)\end{array}$ & $\begin{array}{c}\text { IFN + Ribavirina } \\
(24 \text { semanas) }(\%)\end{array}$ & $\begin{array}{c}\text { IFN + Placebo } \\
\text { (48 semanas) }(\%)\end{array}$ & $\begin{array}{c}\text { IFN + Ribavirina } \\
(48 \text { semanas) }(\%)\end{array}$ \\
\hline Não-1 & $\leq 2 \times 10^{6}$ & 25 & 61 & 36 & 64 \\
Não-1 & $>2 \times 10^{6}$ & 11 & 62 & 26 & 60 \\
1 & $\leq 2 \times 10^{6}$ & 4 & 32 & 25 & 33 \\
1 & $>2 \times 10^{6}$ & 0,8 & 10 & 3 & 27 \\
\hline
\end{tabular}

Há evidências de que a melhor resposta terapêutica obtida com a associação de IFN e ribavirina deve-se fundamentalmente aos menores índices de recidiva após a interrupção do tratamento, já que índices próximos aos $60 \%$ já haviam sido alcançados com doses elevadas de IFN, que não se mantinham após a sua interrupção.

Apenas nos últimos anos, com o desenvolvimento tecnológico e maior confiabilidade nos métodos de biologia molecular para avaliação da carga viral, realizaram-se estudos da cinética de eliminação do VHC, durante seu tratamento com IFN. Após a primeira dose de IFN há queda dos níveis séricos de RNA-VHC em cerca de $40 \%$ nas doses usuais de $3 \mathrm{MU}$ e de $64 \%$ a $84 \%$ nas doses de 5 e $10 \mathrm{MU}$, respectivamente ${ }^{18}$. O pico máximo de queda ocorre após 12 a 24 horas da primeira dose, com tendência de retorno aos níveis anteriores (Figura 5). Assim, o

Hepatite C - viremia pós-Interferon (IFN)

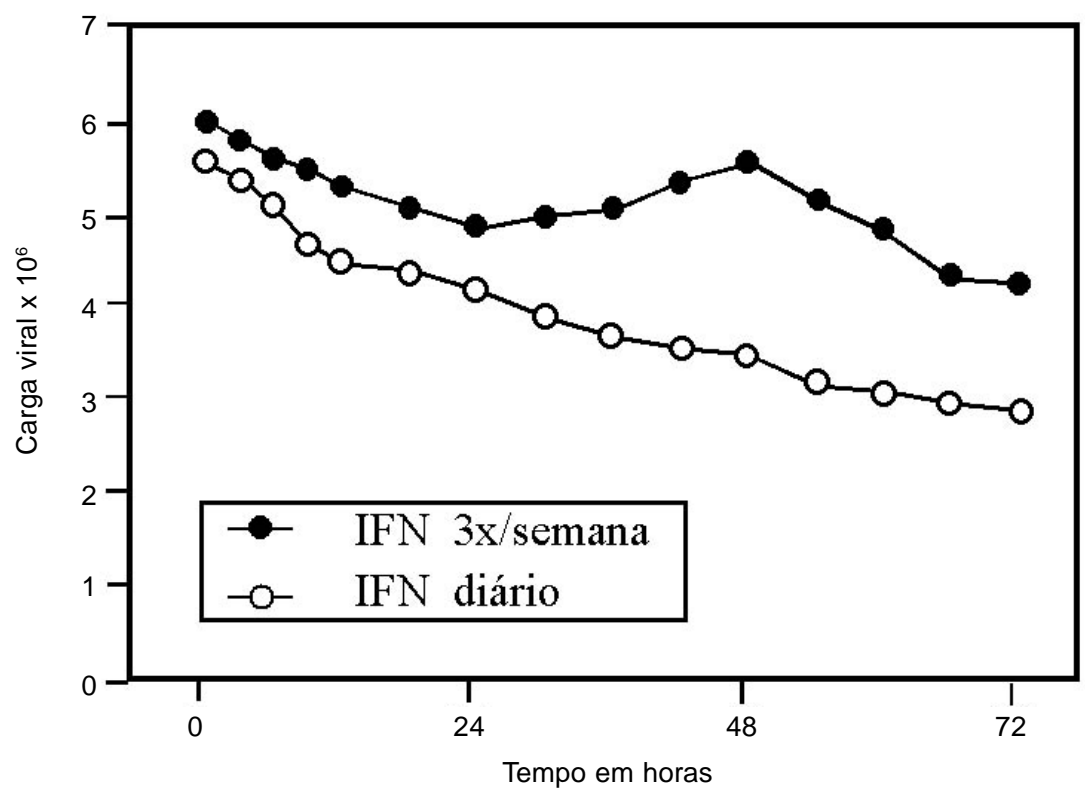

Figura 5 - Os estudos de cinética viral demonstraram queda dos níveis de RNA-VHC que foi contínua nas doses diárias de IFN, sendo intermitente quando usado $3 x$, semana ${ }^{18}$. 
espaçamento de doses, particularmente no início do tratamento pode levar a quedas mais lentas e principalmente ao desenvolvimento de resistência do VHC ao IFN. Os modelos matemáticos para avaliação da cinética viral demonstraram ainda a existência de dois compartimentos, um sérico e outro celular, com comportamentos diferentes em termos de eliminação viral. Embora a vida média do VHC seja curta, em torno de 6 horas, o reservatório intracelular costuma ser muito importante, com 3,7 × 10 ${ }^{11}$ virions/dia ${ }^{18}$ (Figura 5).

O esquema denominado de indução terapêutica utiliza IFN em doses elevadas diárias durante as primeiras semanas do tratamento ( 2 a 4 semanas) seguidas do tratamento convencional de IFN 3MU 3x/semana. Os vários estudos, com monoterapia de IFN, obtiveram índices mais elevados de resposta completa, porém sem a correspondente resposta sustentada ${ }^{34}$. Aguardam-se estudos em que essa interessante alternativa terapêutica tenha sido realizada com a associação de IFN e ribavina.

Outro esquema terapêutico possível é o escalonamento de doses do IFN, que poderia ocorrer no início, ao final ou durante o curso do tratamento. O escalonamento inicial, embora seja interessante em termos de evitar a intensidade dos efeitos colaterais do IFN, mostra-se contra-producente em termos de cinética viral, conforme demonstramos anteriormente. A conduta de ir reduzindo doses de IFN ao final do tratamento também não encontra argumentação plausível na rotina, embora possa ser adotada na segunda ou terceira vez em que se trata pacientes com recaídas ou não-respondedores. Nesses casos, manter a negatividade do RNA-VHC e/ou normalidade de ALT pode depender de doses de IFN < 3MU ou aplicações mais espaçadas, por longos períodos de tempo.

O escalonamento de doses para 4,5MU até $10 \mathrm{MU}$ no curso de tratamento com IFN, é advogado por um grupo de autores, em casos especiais ${ }^{35}$. Determinações seriadas de carga viral são necessárias para que essa atitude possa ser tomada. Os indivíduos que apresentam sensível queda dos níveis de RNA-VHC até o $3^{\circ}$ mês de tratamento convencional, sem negativação, teriam indicação de aumento das doses com monitorização do RNA, o que levaria a maiores porcentagens de respostas sustentadas. Essa atitude precisa ser clinicamente validada em estudos posteriores.

\section{FATORES PREDITIVOS DE RESPOSTA TERAPÊUTICA}

As probabilidades de resposta sustentada ao uso de IFN foram amplamente estudadas ao longo dos últimos anos, podendo ser relacionadas ao hospedeiro, à fase evolutiva da doença ou ao vírus propriamente dito, de forma semelhante ao que ocorre com os fatores preditivos de evolução da hepatite $\mathrm{C}$. Respostas melhores se associam a indivíduos jovens ( $<40$ anos), do sexo feminino e sem cirrose estabelecida. Vários parâmetros laboratoriais como transaminases próximas de valores normais, aumentos de GGT, níveis séricos elevados do ferro e ferritina ou aumento de ferro hepático são considerados de mau prognóstico.

O alcoolismo crônico, ou a simples ingesta alcoólica maior do que $10 \mathrm{~g}$ de etanol puro ao dia, a toxicomania, bem como associações com hepatite $B$ ou HIV também têm sido referidos como indicadores de má resposta terapêutica.

Os fatores ligados ao vírus, entretanto, constituem os indicadores mais fidedignos em termos de avaliarmos, no pré-tratamento e durante o seu curso, as probabilidades de boa resposta terapêutica. Com relação ao genótipo, sabemos que o subtipo 1b, o mais freqüente entre nós, relacionado com contaminação pós-transfusional, é aquele que apresenta a pior resposta terapêutica. Já os tipos 2 e 3 , nos subtipos a ou $b$ costumam apresentar boa resposta terapêutica ao uso de IFN assim como na sua associação com ribavirina. Como os tipos 1a, 4 e 6 mostram-se menos freqüentes, sua avaliação torna-se mais difícil, podendo apresentar comportamento diferente. Nas recentes avaliações sugere-se que os vírus com genótipos 1 apresentam resposta pior enquanto aqueles diferentes de 1 tendem a responder melhor ao tratamento ${ }^{37}$.

A carga viral, ou seja, a determinação sérica da quantidade de genomas virais $/ \mathrm{mm}^{3}$ também parece importante na avaliação da resposta terapêutica. O nível de corte aceito pelos autores é de $2 \times 10^{6}$; quanto menor a carga viral maiores as perspectivas de bons resultados. Além da carga viral pré-tratamento, o acompanhamento da viremia no curso da terapia também se mostrou de importância prognóstica. Quanto mais precoce for o desaparecimento do RNA-VHC da circulação, maiores as probabilidades de resposta sustentada. Assim, quando a negativação do RNA-VHC, pela PCR, ocorre entre 15 e 30 dias após o início do tratamento as porcentagens de resposta sustentada ultrapassam $80 \%$. Se a negativação do RNA-VHC ocorrer até o $3^{\circ}$ mês, as perspectivas continuam boas, embora um pouco menores. Com o uso de IFN isolado aconselhava-se a descontinuidade do tratamento em caso de presença do RNA-VHC após 3 meses de seu início ${ }^{25}$, porém no esquema combinado com ribavirina aguarda-se até o $6^{\circ}$ mes de tratamento, pois ainda há possibilidade de resposta sustentada 4 .

\section{PERSPECTIVAS TERAPÊUTICAS EM FUTURO PRÓXIMO}

A conjugação de Interferon alfa com uma molécula de polietilenoglicol produziu um novo tipo de Interferon, denominado peguilado (Peg), com meia-vida prolongada, cerca de 90 horas. A manutenção do interferon em circulação melhorou sua farmacodinâmica, permitindo ainda um espaçamento maior entre as injeções, que passam a ser semanais. Estudos preliminares para determinar as doses terapêuticas necessárias mostraram que $180 \mathrm{mg}$ de IFN-Peg apresentavam eficácia maior em relação ao IFN padrão, assemelhando-se àquela 
observada com o uso simultâneo de IFN e ribavirina. Os efeitos colaterais revelam-se semelhantes aos descritos pelos pacientes no esquema clássico ${ }^{36}$. Vários ensaios terapêuticos com a associação de IFN-Peg e ribavirina encontram-se em andamento e o produto farmacêutico poderá ser liberado para uso clínico em breve.

Além das drogas disponíveis, há pesquisas em curso sobre novos medicamentos mais eficazes e com poucos efeitos colaterais. Entre eles destacam-se os inibidores das enzimas virais. Já amplamente utilizados para o vírus HIV eles atuariam impedindo a replicação viral. Proteases, helicases e polimerases específicas para o VHC encontram-se em avaliação. Outra abordagem ao tratamento, ainda visando inibir a replicação viral, seria a utilização de oligonucleotídeos e ribozimas, também sujeitas a investigações experimentais.

As citocinas, como as interleucinas 12, 10 e 2, diferentemente das drogas anteriores, atuariam modulando o sistema imunológico, a fim de favorecer a resposta terapêutica. Nessa mesma linha da imunoterapia outras possibilidades estão sendo testadas, inclusive o uso de uma vacina-DNA que, por estimular potente resposta de células $T$ contra o vírus teriam finalidade terapêutica. A complexidade da experimentação com estas novas substâncias passa pela quase certeza de que os melhores resultados serão fruto de uma associação de medicamentos e não de uma droga isolada ${ }^{3}$.

\section{REFERÊNCIAS BIBLIOGRÁFICAS}

1. Benvegnu L, Pontisso P, Cavalletto D, Noventa F, Chemello L, Alberti A. Lack of correlation between hepatitis $C$ virus genotypes and clinical course of hepatitis $C$ virus related cirrhosis. Hepatology 25:211-215, 1997

2. Chutaputti A. Adverse effects and other safety aspects of the hepatitis $\mathrm{C}$ antivirals. Journal of Gastroenterology and Hepatology 15 (Suppl.):E156-E163, 2000.

3. Davis GL, Nelson DR, Reyes GR. Future options for the managemnet of hepatitis C. Seminars in Liver Diseases 19 (Suppl. 1):103-112, 1999.

4. European Association for the Study of the Liver (EASL). International Consensus Conference on Hepatitis C. Journal of Hepatology 30:956-961, 1999.

5. Féray C, Caccamo L, Alexander GJ, Ducot B, Gugenheim J, Casanovas T, Loinaz C,Gigou M, Burra P, Barkholt L, Esteban R, Bizollon T, Lerut J, Minello-Franza A, Bernard PH, Nachbaur K, Botta-Fridlund D, Bismuth $\mathrm{H}$, Schalm SW, Samuel D. European collaborative study on factors influencing outcome after liver transplantation for hepatitis C. Gastroenterology 117:619-625, 1999.

6. Focaccia R, Conceição OJ, Sette Jr H, Sabino E, Bassit L, Nitrini DR, Lomar AV, Lorenço R, Souza FV, Kiffer CR, Santos EB, Gonzales MP, Sáez-Alquézar A, Riscal JR, Fischer D. Estimated prevalence of viral hepatitis in the general population of the municipality of São Paulo, measured by a serologic survey of a stratified, randomized and residence-based population. Brazilian Journal of Infectious Diseases 2:269-284, 1998.

7. Gayotto LCC, Comitê SBP/SBH. Visão histórica e consenso nacional sobre a classificação das hepatites crônicas. Gastroenterologia Endoscopia Digestiva 19:137-140, 2000.

8. Glue P. The clinical pharmacology of Ribavirin. Seminars in Liver Diseases 19(supl. 1):17-24, 1999.

9. Gretch DR. Diagnostic tests for hepatitis C. Hepatology 26(suppl. 1):43S-47S, 1997.

10. Guz B, Strauss E, Takada A, Arruda F, Gayotto LCC. Spontaneous disappearance of serum HCV-RNA in chronic hepatitis. Hepatology 30:203A, 1999.

11. Heathcote EJ, Keeffe EB, Lee SS, Feinman SV, Tong MJ, Reddy KR, Albert DG Jr, Witt K, Blatt LM. Re-treatment of chronic hepatitis C with consensus interferon. Hepatology 27:1136-1143, 1998.
12. Hoofnagle JH, Mullen KD, Jones DB, Rustgi V, Di Biceglie A, Peters M, Waggoner JG, Park Y, Jones EA. Treatment of chronic non-A, non-B hepatitis with recombinant human alpha interferon. A preliminary report. New England Journal of Medicine 315:15751578, 1986

13. Jarvis SM, Thorn JA, Glue P. Ribavirin uptake by human erythrocytes and the involvement of nitrobenzylthioinosinesensitive (es)-nucleoside transporters. British Journal of Pharmacology 123:1587-1592, 1998.

14. Joo M, Habn YS. Animal models for immune defects caused by hepatitis C virus. Molecular Medicine Today 6:167-177, 2000.

15. Kato N, Yoshida H, Ono-Nita SK, Kato J, Goto T, Otsuka M, Lan $\mathrm{KH}$, Matsushima K, ShiratoriY, Omata M. Activation of intracellular signaling by Hepatitis $\mathrm{B}$ and $\mathrm{C}$ viruses: C-viral core is the most potent signal inducer. Hepatology 32:405-412, 2000.

16. Kenny-Walsh $E$. Clinical outcomes after hepatitis $C$ infection from contaminated anti-D immune globulin. Irish Hepatology Research Group. New England Journal of Medicine 340:1228-1233, 1999.

17. Kiyosawa K, Sodeyama T, Tanaka E, Gibo Y, Yoshizawa K, Nakano Y, Furuta S, Akahane Y, Nishioka K, Purcell RH. Interrelationship of blood transfusion, non-A, non-B hepatitis and hepatocellular carcinoma: analysis by detection of antibody to hepatitis $\mathrm{C}$ virus. Hepatology 12:671-675, 1990.

18. Lam NP, Neumann AU, Gretch DR, Wiley TE, Perelson AS, Layden TJ. Dose- dependent acute clearance of hepatitis $C$ genotype 1 virus with interferon alfa. Hepatology 26:226-231, 1997.

19. Lerat H, Berby F, Trabaud MA, Vidalin O, Major M, Trepo C, Inchauspe $G$. Specific detection of hepatitis $C$ virus minus strand RNA in haematopoietic cells. Journal of Clinical Investigation 97:845-851, 1996.

20. Marcellin P. Hepatitis C: clinical spectrum of the disease. Journal of Hepatology 31 (suppl. 1):9-16, 1999.

21. Marcellin P, Lévy S, Erlinger S. Therapy of hepatitis C: patients with normal aminotransferase levels. Hepatology 26 (suppl. 1):133S-136S, 1997.

22. McHutchison JG, Gordon SC, Schiff ER, Shiffman ML, Lee WM, Rustgi VK, Goodman ZD, Ling MH, Cort S, Albrecht JK. Interferon alfa-2b alone or in combination with ribavirin as initial treatment for chronic hepatitis C. New England Journal of Medicine 339:1485-1492, 1998 
23. McHutchison JG, Poynard T. Combination therapy with interferon plus ribavirin for the initial treatment of chronic hepatitis $\mathrm{C}$. Seminars in Liver Diseases (suppl. 1):47-65, 1999.

24. Missale G, Bertoni R, Lamonaca V, Valli A, Massari M, Mori C, Rumi MG, Houghton M, Fiaccadori F, Ferrari C. Different clinical behaviors of acute hepatitis $\mathrm{C}$ virus infection associated with diferent vigor of the anti-viral cell-mediated immune response. Journal of Clinical Investigation 98:706-714, 1998.

25. National Institutes of Health. Management of Hepatitis. NIH Consensus Statement Online Mar 24-26, 1997.

26. Pessione F, Degos F, Marcellin P, Duchatelle V, Njapoum C, Martinot-Peignoux M, Degott C, Valla D, Erlinger S, Rueff B. Effect of alcohol consumption on serum hepatitis $C$ virus RNA and histological lesions in chronic hepatitis C. Hepatology 27:17171722, 1998

27. Pileri P, Uematsu Y, Campagnoli S, Galli G, Falugi F, Petracca R, Weiner AJ, Houghton M, Rosa D, Grandi G, Abrignani S. Binding of hepatitis C virus to CD81. Science 282:938-941, 1998.

28. Poynard T, Marcellin P, Lee SS. Randomised trial of interferon alfa-2b plus ribavirin for 48 weeks or for 24 weeks versus interferon alfa-2b plus placebo for 48 weeks for treatment of chronic infection with hepatitis C virus. Lancet 352:1426-1432, 1998.

29. Rosen HR, Gretch DR. Hepatitis C virus: current understanding and prospects for future therapies. Molecular Medicine Today 5:393-399, 1999.

30. Schiff ER, Medina M, Kahn RS. New perspectives in the diagnosis of hepatitis C. Seminars in Liver Diseases 19(suppl. 1):3-15, 1999.

31. Schwimmer JB, Balistreri WF. Transmission, natural history, and treatment of hepatitis $\mathrm{C}$ virus infection in the pediatric population. Seminars in Liver Diseases 20:37-46, 2000.

32. Seeff LB, Buskell-Bales Z, Wright EC, Durako SJ, Alter HJ, Iber FL, Hollinger FB, Gitnick G, Knodell RG, Perrillo RP, Stevens CE, Hollingsworth CG. The National heart and lung study group. Longterm mortality after transfusion-associated non-A, non-B hepatitis. New England Journal of Medicine 327:1906-1911, 1992.

33. Sherman KE, Sjogren M, Creager RL, Damiano MA, Freeman S, Lewey S, Davis D, Root S, Weber FL, Ishak KG, Goodman ZD. Combination therapy with thymosin alpha 1 and interferon for the treatment of chronic hepatitis $\mathrm{C}$ infection: a randomized, placebocontrolled double-blind trial. Hepatology 27:1128-1135, 1998.

34. Shiffman ML. Use of high-dose interferon in the treatment of chronic hepatitis C. Seminars in Liver Diseases 19(suppl. 1):2533, 1999.
35. Shiffman ML, Hofmann CM, Luketic VA, Thompson EB, Sanyal AJ. Treatment of chronic hepatitis $C$ with escalating doses of interferon alpha- $2 b$ increases both biochemical and virologic response. Hepatology 22:152A, 1995.

36. Shiffman ML, Pockros PJ, Reddy RK, Wright TL, Reindollar R, Clin C. A controlled, randomized, multicenter, descending dose phase II trial of pegylated interferon alpha-2A (PEG) vs standard interferon alpha-2A (IFN) for treatment of chronic hepatitis C. Gastroenterology 116 (suppl):A1275, 1999.

37. Shiratori Y, Omata M. Predictors of the efficacy of interferon theraphy for patients with chronic hepatitis $C$ before and during therapy: how does this modify the treatment course? Journal of Gastroenterology and Hepatology 15 (suppl):E141-E151, 2000.

38. Soriano V, Garcia-Samaniego J, Rodriguez-Rosado R, González J, Pedreira J. Hepatitis C and HIV infection: biological, clinical and therapeutic implications. Journal of Hepatology 31 (suppl. 1):119-123, 1999.

39. Strauss E, Guz B, Fernandes HS, Almeida AL, Chamone DAF. Epidemiology of Hepatitis C in São Paulo - Brazil. In: IX Triennial International Symposium on Viral hepatitis and Liver Disease, Chicago, p. 188, 1996.

40. Tanaka E, Ohue C, Aoyagi K, Yamaguchi K, Yagi S, Kiyosawa K, Alter HJ. Evaluation of a new enzyme immunoassay for Hepatitis $\mathrm{C}$ virus (HCV) core antigen with clinical sensitivity approximating that of genomic amplification of HCV RNA. Hepatology 32:388393, 2000 .

41. Tong MJ, El-Farra NS, Reikes AR, Co RL. Clinical outcomes after transfusion- associated hepatitis C. New England Journal of Medicine 332:1463-1466, 1995.

42. Valla D, Chevallier M, Marcellin P, Payen JL, Trépo C, Fonck M, Bourliere M, Boucher E, Miguet JP, Parlier D, Lemonnier C, Opolon $P$. Treatment of hepatitis $C$ virus-related cirrhosis: a randomized controlled trial of interferon alpha-2b versus non treatment. Hepatology 31:1870-1875, 1999.

43. Younossi ZM, Perrillo RP. The roles of Amantadine, Rimantadine, Ursodeoxycholic Acid, and NSAIDs, alone or in combination with Alpha Interferons, in the treatment of chronic hepatitis C. Seminars in Liver Diseases 19 (Suppl. 1):95-102, 1999.

44. Wasley A, Alter MJ. Epidemiology of hepatitis C: geographic differences and temporal trends. Seminars in Liver Diseases 20:116, 2000.

45. Zaaijer HL, Cuypers HT, Reesink HW, Winkel IN, Gerken G, Lelie $\mathrm{PN}$. Reliability of polymerase chain reaction for detection of hepatitis C virus. Lancet 341:722-724, 1993. 